\title{
The Case for Infusing Quantitative Literacy into Introductory Geoscience Courses
}

Jennifer M. Wenner

University of Wisconsin Oshkosh, wenner@uwosh.edu

Eric M. Baer

Highline Community College, ebaer@highline.edu

Cathryn A. Manduca

Carleton College, cmanduca@carleton.edu

R. Heather Macdonald

The College of William and Mary, rhmacd@wm.edu

Samuel Patterson

Carleton College, spatters@carleton.edu

See next page for additional authors

Follow this and additional works at: https://digitalcommons.usf.edu/numeracy

Part of the Mathematics Commons, and the Science and Mathematics Education Commons

\section{Recommended Citation}

Wenner, Jennifer M., Eric M. Baer, Cathryn A. Manduca, R. Heather Macdonald, Samuel Patterson, and Mary Savina. "The Case for Infusing Quantitative Literacy into Introductory Geoscience Courses."

Numeracy 2, Iss. 1 (2009): Article 4. DOI: http://dx.doi.org/10.5038/1936-4660.2.1.4 


\title{
The Case for Infusing Quantitative Literacy into Introductory Geoscience Courses
}

\begin{abstract}
We present the case for introductory geoscience courses as model venues for increasing the quantitative literacy (QL) of large numbers of the college-educated population. The geosciences provide meaningful context for a number of fundamental mathematical concepts that are revisited several times in a single course. Using some best practices from the mathematics education community surrounding problem solving, calculus reform, pre-college mathematics and five geoscience/math workshops, geoscience and mathematics faculty have identified five pedagogical ideas to increase the QL of the students who populate introductory geoscience courses. These five ideas include techniques such as: place mathematical concepts in context, use multiple representations, use technology appropriately, work in groups, and do multiple-day, in-depth problems that place quantitative skills in multiple contexts. We discuss the pedagogical underpinnings of these five ideas and illustrate some ways that the geosciences represent ideal places to use these techniques. However, the inclusion of QL in introductory courses is often met with resistance at all levels. Faculty who wish to include quantitative content must use creative means to break down barriers of public perception of geoscience as qualitative, administrative worry that enrollments will drop and faculty resistance to change. Novel ways to infuse QL into geoscience classrooms include use of web-based resources, shadow courses, setting clear expectations, and promoting quantitative geoscience to the general public. In order to help faculty increase the QL of geoscience students, a community-built faculty-centered web resource (Teaching Quantitative Skills in the Geosciences) houses multiple examples that implement the five best practices of QL throughout the geoscience curriculum. We direct faculty to three portions of the web resource: Teaching Quantitative Literacy, QL activities, and the 2006 workshop website - Infusing Quantitative Literacy into Introductory Geoscience Courses. These portions of the website are designed to give geoscience faculty the resources they need to infuse quantitative content into their entry-level courses, thereby building the QL of the students who enroll. The infusion of QL in the introductory geoscience classroom allows faculty to realistically represent the quantitative nature of the science to the students who may need it most. Ultimately, the inclusion of pedagogically sound quantitative activities and exercises will serve to increase QL of our educated citizenry.
\end{abstract}

\section{Keywords}

quantitative literacy, geosciences, pedagogy, web resources, entry-level

\section{Creative Commons License}

\section{(i) (9)}

This work is licensed under a Creative Commons Attribution-Noncommercial 4.0 License

\section{Authors}

Jennifer M. Wenner, Eric M. Baer, Cathryn A. Manduca, R. Heather Macdonald, Samuel Patterson, and Mary Savina 


\section{Introduction}

Quantitative literacy (QL) is more than calculation or solving equations. The quantitatively literate can reason with data, solve quantitative problems, and understand the importance of numbers in everyday life (Gal 1997; Steen 1997, 2001, 2004; Richardson and McCallum 2003; Madison and Steen 2003). Modern society requires its citizens to reason with and discern the importance of statistical, scientific and sociological data to make informed decisions about many significant issues (e.g., Gal 1997). Many colleges and universities across the United States recognize the need for quantitatively literate citizens and are designing or have implemented QL requirements for graduating students. These requirements may be in or outside mathematics departments and often involve redesign of pre-existing physical science courses (including the geosciences) to include QL. We argue that introductory geoscience courses represent an ideal venue for infusing QL into our citizenry because the geosciences are real-world applications of physics, chemistry, mathematics, and engineering. If, as many science, technology, engineering and mathematics (STEM) educators (e.g., Adams and Hamm 1998; Bailey 2000a) suggest, students are more likely to be interested in mathematics when it is placed in relevant context, the geosciences are the inevitable place to increase QL.

Geoscience faculty recognize the need and opportunity for the geosciences to contribute to the development of a quantitatively literate citizenry (e.g., Macdonald and Bailey 2000; Macdonald et al. 2000; Manduca et al. 2001, 2005, 2008; Wenner et al. 2004, 2005, 2006a, b; Hancock and Manduca 2005). Traditionally, many students enroll in introductory geoscience courses because they wish to avoid disciplines they perceive as quantitative and mathematical (e.g., physics, mathematics and chemistry) and may identify the geosciences as largely descriptive or remedial (e.g., Shea 1990; Corbett 2000). Ironically, the very disciplines students may be avoiding are applied to geologic problems in introductory geoscience on a regular basis. Because students who populate geoscience courses are often least likely to be literate in quantitative methods and the geosciences can provide the much needed context for quantitative skills, entry-level geoscience instructors have an opportunity to make a significant impact on the overall QL of the college-educated population.

Several workshops over the past 10 years (held by Project Kaleidoscope [PKAL] in 1999; and the National Association of Geoscience Teachers [NAGT] in 2002, 2004, 2005, and 2006) identified and explored ways in which introductory geoscience courses can serve as a cornerstone in the development of the QL of students. Workshop participants identified appropriate quantitative subjects in the geosciences, produced examples of ways for geoscience educators to successfully incorporate QL into their courses, and addressed concerns about 
student and faculty misperceptions that including QL may harm course or student evaluations. The workshop activities, syllabi and discussions melded research from mathematics and geoscience education to define five ideas that can increase geoscience students' QL and resulted in a series of pedagogically based community-built Web resources for faculty. These teaching resources focus on college-level teaching, use demonstrated best practices, and can be adapted to fit a variety of courses. Most are peer reviewed.

\section{QL and Introductory Geoscience Courses}

Many researchers have noted that in order to achieve QL, students need repeated opportunities to develop their QL skills, to apply QL in a wide variety of contexts, and to practice using QL skills in critical situations (Steen 2004; Madison and Steen 2003). Mathematical concepts such as graphs, unit conversions, basic algebra, probability, and many others recur in differing contexts during a single introductory geoscience course. Many of these quantitative applications involve natural phenomena that are familiar, even intuitive, to students and can provide ideal situations that build student confidence and reinforce fundamental mathematical skills. Furthermore, the geosciences abound in examples where quantitative information applies to personal and societal decision making (e.g., energy policy, climate change, sustainability). Instructors at the introductory level can capitalize on the wealth of opportunities for students to apply fundamental math (and physics, chemistry and biology) skills in the rich context of natural geoscience systems, thus helping students build their QL (see Journal of Geoscience Education, v. 43 no. 2 and articles therein).

Geoscience courses that serve a broad campus population (e.g., introductory courses meeting general education requirements) provide an important pathway for a large number of non-science majors to develop the quantitative skills they need to be effective citizens. Textbook companies estimate that 350,000-400,000 students enroll in introductory geoscience courses each year (Martinez and Baker 2006). In this setting, geoscience faculty have the opportunity to use the context of the geosciences to help students apply quantitative reasoning to engaging problems.

\section{Lessons Learned From Mathematics: Five Ideas for Teaching QL}

If the delivery of QL in introductory geosciences is to be successful, quantitative materials for geoscience courses must be pedagogically sound, easily adaptable to any course, supported by faculty and departments, and relevant to students' lives. To support faculty in creating pedagogically sound materials, PKAL, NAGT, and 
the Digital Library for Earth System Education (DLESE) sponsored several faculty workshops in the past decade to identify key concepts to guide the teaching of QL (all were funded by the National Science Foundation [NSF]). At one such NSF-funded workshop on Teaching Quantitative Skills in 2002, mathematics and geoscience faculty combined lessons learned from a PKAL workshop held at William and Mary in 1999, calculus reform (e.g., Steen 1988), problem solving strategies (e.g., Schoenfeld 1992), and work on pre-college mathematics (AMATYC 1995; Anderson and Swanson 2004), to generate a list of five "good ideas" for teaching and learning quantitative skills:

1. place mathematical concepts in context;

2. use multiple representations;

3. use technology appropriately;

4. work in groups; and

5. do in-depth problems that last more than one day and revisit quantitative skills frequently.

When viewed through the lens of these five ideas, the geosciences can be a model subject through which to increase students' QL. The five teaching ideas also established the basis of several subsequent workshops on QL in the geosciences (held at Carleton College in 2004, 2005, and 2006) and form the pedagogical underpinnings of the Teaching Quantitative Literacy Web site (Manduca et al. 2008). Below, we discuss the educational basis for each of the five ideas and ways that the geosciences provide ample opportunity to use these ideas to increase QL.

Place mathematical concepts in context. Scientific and mathematical inquiry uses appropriate quantitative skills in the context of a question or problem. Some researchers in mathematics education are concerned with making students mathematically powerful - capable of making connections, raising questions, using numerous mathematical techniques and testing and verifying mathematical models (e.g., Adams and Hamm 1998; Silver 1985). Adams and Hamm (1998) write "mathematically powerful work is purposeful. It may be motivated by curiosity, whimsy, or need, but it will always seem more significant to the student if it has a sense of purpose." Scientific inquiry in an introductory geoscience course can provide a sense of purpose for the students. Many students have already formulated meaningful questions about Earth systems and are motivated to address quantitative problems on their own when they engage in a subject of personal interest (Adams and Hamm 1998).

Because the geosciences are based in observational data, many geoscience topics lend themselves to teaching with data sets (collected by students or 
otherwise), plotting data, generating mathematical models for the relationship between two variables, and understanding uncertainty. Many students are concerned about the issue of global warming and the role of $\mathrm{CO}_{2}$ in climate change. Randy Richardson (University of Arizona) uses this interest in the natural world to increase the QL of students in his introductory geoscience course. He employs an in-class activity ${ }^{1}$ where students work in groups to plot monthly $\mathrm{CO}_{2}$ data on overheads and estimate the rate of change over five years. Student groups plot random data points from a larger data set on a preprinted overhead and approximate a best-fit line through their data. Variation is considerable among the groups. The overheads are collected and stacked to show that $\mathrm{CO}_{2}$ variation is not linear (variation occurs seasonally). Discussion ensues and can touch on global averages, estimating a best-fit line, sampling bias, and many other quantitative issues. Although only one example, Richardson's activity can be adapted for use with any timely data-rich geoscience issue.

The timeliness of topics in the geosciences provides context for students to fully engage in solving geoscience problems with practical mathematical applications. Mathematical concepts and geologic context are intimately intertwined - using students' basic mathematical skills and intuition about Earth in introductory geoscience provides the kind of context that is crucial to building university-level students' QL. Geoscience can provide interesting and worthwhile quantitative questions and problems for students to work through so that they recognize the value of mathematics in everyday life (Bailey 2000a). Most students have some intuition about Earth materials - for example, students have a feel for how "heavy" a rock should be and know that water flows downhill. Furthermore, the majority of quantitative problems in introductory geoscience courses require no more than the algebra or geometry most college-bound students learn in high school. Geologic problems that connect their intuition to fundamental mathematics illustrates for students that they may already "do math" without even knowing it. Early in the course, explicit reminders of mathematical process and help with connecting math to geology may be required; however, most students respond well when they prove to themselves that they already have the needed mathematical skills (Bailey 2000a; NAGT workshop in 2002).

Doing mathematics with a "sense of purpose" or putting mathematics in context also helps students transfer skills from mathematics classes to other courses. Many undergraduate mathematics courses are geared toward theoretical concepts and manipulation of symbols (in particular the variables $x$ and $y$ ). When students arrive in a science course and are asked to construct an equation or graph, they often have difficulty connecting theory to their own observations

\footnotetext{
${ }^{1}$ http://serc.carleton.edu/introgeo/interactive/examples/co2.html: "Starting Point: Teaching Entry Level Geoscience: Carbon Dioxide Exercise" by Randy Richardson and R.E. Teed (accessed 31 December 2008).
} 
(e.g., Hall-Wallace 2000). For example, many scientific data sets can be described by linear relationships and most students know the equation for a line ( $y$ $=m x+b)$. However, when asked to write an equation for a linear plot of distance vs. time (or any variables other than $x$ and $y$ ), students are unable to express the relationship appropriately (e.g., Hall-Wallace 2000). Educators can address this issue by introducing a linear geologic relationship that is familiar to many students (e.g., the Hawaii hot spot movement; Hall-Wallace 2000) and then scaffolding increasingly difficult linear relationships. Other mathematical concepts that can be connected to geoscience applications through increasingly difficult problems include probability, rates, orders of magnitude, etc. (e.g., Bailey 2000a). When instructors explicitly connect students' geologic observations and skills to their mathematical underpinnings (e.g., Lutz and Srogi 2000; Baer et al. 2005), students may begin to recognize the power of mathematics for understanding the natural world.

Use multiple representations. Education research suggests that students benefit greatly from multiple representations of a mathematical concept (e.g., DufourJanvier et al. 1987; Kaput 1992; Jiang and McClintock 2000; National Council of Teachers of Mathematics [NCTM] 2000; Schultz and Waters 2000; Friedlander and Tabach 2001). The use of multiple representations increases student learning in both mathematics and science courses when linkages are made among representations (e.g., NCTM 2000; Jiang and McClintock 2000; Ozgun-Koca 2001; Pape and Tshoshanov 2001). The phrase "multiple representations" means something very specific to mathematicians: quantitative concepts represented verbally, numerically, graphically, and algebraically (e.g., Steen 1988; AMATYC 1995; Friedlander and Tabach 2001; Anderson and Swanson 2004). In the geosciences, we also represent quantitative geoscience information multiple ways - physical models, maps, visualizations, graphs that have more than mathematical information on them, as well as the many representations recognized by mathematicians. Although this is a broader view of the definition of multiple representations, their use is pervasive in the geosciences and the benefits to student learning are the same. The strength of the geosciences for infusing QL lies in the existing recognition that students need multiple ways to view and understand a given concept, whether it be mathematical or scientific.

Use of multiple vocabularies and representations increases student learning (as noted above) but may also be a barrier to students' understanding of mathematical skills and their application in the sciences. Challenges arise when common quantitative skills are presented differently, with widely ranging language and symbols (Anderson and Swanson 2004). For example, many fields present the equation for a line where the independent variable is not $x$ but rather some other variable such as $T$ for temperature. In the geosciences, graphical representations are often turned on their heads to show pressure increasing 
downwards in the Earth or variation in chemical composition with stratigraphic position. These differences can lead to student perceptions that there is no connection between required mathematics courses and the geosciences (e.g., Lutz and Srogi 2000). Instructors can overcome these challenges and become more effective teachers of QL by increasing communication about connections among applications, recognizing differences in language and symbology, and explicitly connecting distinct representations of the same concept (Manduca et al. 2008).

Mathematics and science curricula that represent mathematical concepts in a variety of forms acknowledge diverse student learning styles (e.g., Gardner 1983; Fleming and Mills 1992; Bykerk-Kauffman 1995). Armed with an arsenal of representations that speak to an individual's own learning style, students can explore multiple approaches to a problem and more readily attain comfort with the mathematics (Pape and Tchoshanov 2001). Physics education has pioneered a method that acknowledges the variety of approaches that exist for solving a given problem (Heller and Heller 1999) and allows students to progress from novice to expert problem solvers by encouraging them to explore their own problemsolving approaches (e.g., Boller 1999; Redish and Steinberg 1999). At the University of Minnesota, students are given a worksheet ${ }^{2}$ to use for problem solving that has space for drawing pictures, diagramming and defining quantities, constructing equations, solving equations, and evaluating the outcome. Students create and explore the connections among their different models of physical reality and the mathematical underpinnings, thereby increasing their problemsolving ability and arriving at a deeper understanding of the mathematics (Pape and Tchoshanov 2001; Schultz and Waters 2000; Greeno and Hall 1997).

Many introductory geoscience textbooks encourage students to explore multiple approaches to solving problems. Data tables, graphs, visualizations, and physical models (two- and three-dimensional) of a given concept commonly appear in these texts (e.g., Smith and Pun 2005; Marshak 2007). These same textbooks, however, often fall short by failing to connect numbers and mathematical symbols to models and graphs that describe natural phenomena (e.g., Shea 1990, 1994). The Teaching Quantitative Skills Web site exists to support faculty in generating appropriate symbolic and numerical representations to eliminate these deficiencies. Instead of struggling to find ways to present difficult mathematical concepts, faculty will find examples of the many representations that exist for a given quantitative concept. Furthermore, the Web site addresses student stumbling blocks and provides "troubleshooting" advice for faculty to help students transfer QL skills among geoscience topics.

\footnotetext{
${ }^{2} \mathrm{http} / / /$ serc.carleton.edu/files/quantskills/workshop06/heller_presentation_tuesday.ppt, Slide 16 from presentation "Teaching Problem Solving in Large Introductory Classes: The View from Physics" by Ken Heller at SERC workshop 2006 (accessed 31 December 2008).
} 
Use technology appropriately. The NCTM (2000) identified technology as one of the six goals for school mathematics, stating: "Technology is essential in teaching and learning mathematics; it influences the mathematics that is taught and enhances student learning." Many mathematics researchers and instructors incorporate technology to enhance learning (e.g., Jacobson and Kozma 1999), particularly to connect multiple representations (e.g., Alagic 2003; Ozgun-Koca 2001; Jiang and McCormick 2000). Computers and graphing calculators allow students to produce their own representations by graphing an equation or by writing an equation that models their own observations about some physical phenomenon. This empowers students to perform mathematics that they may not otherwise have been able to do and stimulates higher-order thinking as long as they understand both the mathematical and technological underpinnings of the procedures and can recognize their connections to a given application (Alagic 2003).

The geosciences are ideal for implementing technology to illustrate quantitative skills. Mathematical programs/packages including MatLab, Mathematica, Excel, Stella and others are appropriate for teaching quantitative geologic topics and increasing QL. Whereas not all of these tools are appropriate for every introductory geoscience course and many instructors in the geosciences are not comfortable with the mathematics software packages or graphing calculators, technologically literate university students benefit from applying these tools to disciplines beyond mathematics. Geoscientists may need to work with colleagues in mathematics and other science departments to develop these technological skills and then decide on appropriate places to incorporate them into their courses. Furthermore, these quantitative tools should be introduced across the entire geoscience curriculum to encourage proficiency in both quantitative skills and technology.

Because Excel is so pervasive in higher education, it represents a readily available quantitative and technological tool for students to use in quantitative problem solving. Geoscientists have recognized the power of spreadsheets as a teaching tool since the mid-1980's (e.g., Manche and Lakatos 1986; Ousey 1986; Fratesi and Vacher 2005; Vacher 2005). At the University of South Florida, geoscience faculty members have made a concerted effort to use Excel to increase both quantitative and technological skills of students in all of their courses (McGee et al. 2007). Len Vacher at USF promoted the use of spreadsheets as a technological tool to bring quantitative literacy to students through contextual problems and has a library ${ }^{3}$ of modules for courses throughout the geology curriculum, as well as examples from other disciplines. In addition, many of the examples provided on the Teaching Quantitative Literacy Web site take

${ }^{3}$ http://serc.carleton.edu/sp/ssac: "Teaching with Spreadsheets Across the Curriculum" by Len Vacher (accessed 31 December 2008). 
advantage of the growing use of important technologies such as spreadsheets, graphing calculators and GPS units.

Work in groups. Many researchers in mathematics education recognize the effectiveness of collaborative teaching and learning (e.g., Johnson and Johnson 1989; Adams and Hamm 1990, 1998; Davidson 1990; Johnson et al. 1998; Rogers et al. 2001). Instructor responses to the Project CLUME ${ }^{4}$ (Collaborative Learning in Undergraduate Mathematics Education) Survey ${ }^{5}$ indicate that approximately $80 \%$ of students react positively to collaborative learning approaches in mathematics classrooms. Instructors also report improvements in attitude and confidence, deeper understanding of the mathematics, and decreases in math anxiety (Baker and Hagelgans 2001). In cooperative learning, students become active participants in their own education and have a venue to share and defend problem-solving logic (Dees 1991; Davidson et al. 2001). It also provides social support for learning mathematics and shows students that they are not alone in their struggles (Davidson et al. 2001). When a cooperative environment is well organized, students learn to recognize and draw on one another's skills and, because they work with their peers, may be willing to explore another's alternative approach to a problem (Millis and Cottell 1998; Davidson et al. 2001). The NCTM (2000) has suggested that the use of small groups along with other innovative teaching methods may help instructors accomplish NCTM curriculum standards. Many in the mathematics community embrace the notion of using collaborative inquiry to instill better problem-solving approaches and mathematical skills in students.

The geosciences are particularly geared toward collaboration - few geoscientists work alone; rather, they need experts in a variety of subdisciplines to address complex questions that are important to the field (Fratesi and Vacher 2008). Geoscience educators have long encouraged students to participate in collaborative/cooperative learning exercises; an entire issue of The Journal of Geological Education (September 1995) is devoted to collaborative work in geoscience courses. The simple addition of a quantitative component to preexisting group work or projects can take little effort on the part of instructors and may lead students to achieve a deeper understanding of quantitative geological topics as well as any associated mathematical concepts.

Do in-depth problems that last more than one day and revisit quantitative skills frequently. Students develop problem-solving skills when given sufficient time to think and work on problems (e.g., Silver 1985). Thompson (1985) argues

\footnotetext{
${ }^{4}$ http://www.uwplatt.edu/clume/index.html: "The Mathematical Association of America's Project CLUME" (accessed 31 December 2008)

${ }^{5}$ http://www.uwplatt.edu/clume/survey/index.htm: Untitled page by Anthony D. Thomas (accessed 31 December 2008).
} 
that because learning mathematics is essentially a reflective activity, students need time to reflect and internalize mathematical concepts. Exercises that scaffold several techniques can be completed over the duration of more than one class period and give students the experience, reflection and repetition that is essential to learning important mathematical concepts (NAGT workshop in 2002). By integrating multiple mathematical techniques into a single larger, morecomplex problem, students are also given the chance to take some responsibility for their own learning and to learn to make decisions about quantitative tasks (Barrows and Tamblyn 1980; Oberlander and Talbert-Johnson 2004). Problembased learning (PBL) and project-based math (PBM) are examples of successful ways that mathematics instructors are using this pedagogy (e.g., Stevens 2000).

Introductory geoscience courses can follow two possible models when incorporating quantitative literacy over multiple days:

1. Repetitive use of the same mathematical concept in multiple geoscience contexts. Introductory geosciences lend themselves to repeated opportunities to apply a given mathematical concept in a number of geologic contexts. For example, recurrence interval and probabilities apply to earthquakes, flooding, and hurricanes; topics such as population growth, radioactive decay and earthquake magnitude all use exponential functions, and there are few chapters in geoscience textbooks that do not include graphs of data. Instructors can scaffold increasingly complex quantitative concepts into a single course, giving students time to internalize previously encountered material before revisiting it in another context (Kenyon 2000). Multiple uses and examples of the same quantitative skill encourage students to make connections between different parts of a single course (or among multiple courses; e.g., Steen 2004; Madison and Steen 2003). Although many math concepts recur multiple times in a student's schooling, instructors often find that students have difficulty connecting quantitative skills among "non-math" topics. When students are explicitly reminded that they have previously encountered the material, they more readily recognize the application in a variety of contexts. Students who are made aware that they have already encountered a concept may be better able to use quantitative skills in many contexts and feel more comfortable and confident in their mathematical abilities.

2. Project-based learning. The geosciences are also ideal for taking advantage of multiple-day projects - many faculty already incorporate multiple-week (or longer) projects into introductory courses (e.g., Furman and Merritt 2000). Even in a large class, a data-intensive research project can provide a meaningful quantitative science experience for students. An 
example that also incorporates many of the other pedagogical ideas discussed above has up to 100 introductory geoscience students work in teams to research the climate of Africa (Furman and Merritt 2000). Student teams examine temperature and precipitation data from a specific region of Africa and are asked to investigate evidence for climate change over the 100-year period of record (Furman and Merritt 2000). Throughout the semester, students learn skills related to data assessment, spreadsheet manipulation and statistical analysis (Furman and Merritt 2000). The broad range of topics covered in introductory geoscience courses present instructors with a wealth of possible project topics. Furthermore, increasing availability of peer-reviewed and published datasets online $^{6}$ allows students to collect and analyze data relevant to any topic. Design of a quantitative project- based learning assignment for introductory geoscience depends only on the interests of the instructor and/or the students.

These five pedagogical ideas for teaching QL to introductory geoscience students can serve as a model for ways to infuse quantitative concepts realistically throughout the courses that serve the greater population of college students.

\section{Breaking Barriers to QL in Entry-Level Geoscience}

With the five pedagogical ideas in mind, survey courses in the geosciences provide the ideal venue for increasing the QL of university students. Furthermore, all subdisciplines in the geosciences have quantitative applications, and instructors more realistically represent the discipline when quantitative problem solving is included in introductory geoscience courses. Yet, the persistent student misconception that entry-level geoscience courses are a safe haven for math-phobic students presents challenges to faculty who wish to provide students with a realistic quantitative treatment of the science. In a survey

${ }^{6}$ Examples:

- http://www.census.gov/ipc/www/idb: "U.S. Census Bureau, International Data Base" for population data(accessed 31December 2008);

- http://www.ncdc.noaa.gov/oa/ncdc.html: "NOAA Satellite and Information Service: National Climatic Data Center, for climate data(accessed 31 December 2008);

- http://www.geokem.com/ "Geochemistry of Igneous Rocks: Geokem" for igneous geochemistry (accessed 31 December 2008);

- http://geoportal.kgs.ku.edu/earthchem/portal: "Earthchem, Advanced Data Management in Solid Earth Geochemistry" (accessed 31 December 2008);

- http://navdat.kgs.ku.edu/: "NAVDAT, The North American Volcanic and Intrusive Rock Database" (accessed 31 December 2008). 
of US geoscience faculty, $80-85 \%$ reported that they include quantitative problems in their entry-level courses; yet only $20-25 \%$ included them on a weekly basis and far fewer on a daily basis (Macdonald et al. 2004). The perception of the geosciences as largely qualitative exists for a variety of reasons: textbooks avoid rigorous treatment of math (Shea 1990), students perpetuate the "Rocks for Jocks" myth, and high schools offer Earth Science as remedial science. Participants at PKAL and NAGT workshops between 1999 and 2006 suggested that many faculty view the geosciences as quantitative but worry about including QL in their courses (Manduca et al. 2001; Wenner et al. 2004, 2005; 2006a; Hancock and Manduca 2005; Manduca et al. 2008). At a QL workshop in 2006, 29 geoscientists built a collection of resources for infusing QL into introductory geoscience courses (Wenner et al. 2006a) and to generate solutions to some of these obstacles.

\section{Public Perception and Textbook Representation}

Too often, quantitative skills and mathematical concepts are de-emphasized in geoscience textbooks in favor of qualitative exposition. Shea (1990) found that more than half of the introductory geology textbooks he examined had little or no mathematical content. The few textbooks that include equations do not provide end-of-chapter questions using mathematical concepts or work through the application for students (Shea 1990). As a result, members of the general public (and thus, university students) perceive that mathematical problems are unrelated to introductory geoscience. Many high schools add to this perception by offering Earth Science as the science class for non-college bound students. Consequently, few established/published quantitative geoscience examples exist and faculty have difficulty finding guidance for effectively incorporating quantitative exercises into their entry-level courses. This lack of textbook support discourages inclusion of quantitative concepts and diminishes the likelihood of success when QL is included.

In the past decade, significant effort has been put forth to design effective quantitative activities for the introductory-level geoscience courses (e.g., Bailey 2000b; Furman and Merritt 2000; Guertin 2000; Kenyon 2000; Shosa et al., 2000; six workshops from 1999 to 2006). With a small amount of effort, faculty can supplement textbook materials with published activities and those posted to the Teaching Quantitative Skills Web site (see above) to supplement textbook materials. Use of resources on the Teaching Quantitative Literacy Web site can also help with the appropriate level of instruction to build quantitative skills into an introductory course. Many faculty at the 2006 workshop already use activities that are infused with quantitative skills, covering a wide range from in-class to semester long projects. Some illustrative examples include: 
- A short homework/in-class activity involving students' environmental footprint. $^{7}$

- A single laboratory activity using a dataset collected from the USGS to evaluate the economic and personal loss associated with flooding. ${ }^{8}$

- A multiple-session lab involving geologic cross-sections and their interpretation. $^{9}$

- A semester-long project involving an investigation of the causes of anoxia in the Gulf of Mexico. ${ }^{10}$

Many more examples can be found on the 2006 workshop activities page ${ }^{11}$ and within the Teaching Quantitative Skills activities collection. ${ }^{12}$ Most of these activities have been classroom tested and can be adapted to fit many different courses. Many Web contributors hope that the availability of these easily adaptable activities and assignments will drive geoscience textbook companies to include quantitative content in future additions.

\section{Expectations and Attitudes - Public, Students and Faculty}

A change in the way high school curricula represent the geosciences will go a long way to changing the attitude of the public about the "math-free" nature of the science. Two high school teachers attended the 2006 workshop and discussed their view of geoscience courses as the "capstone" experience for students interested in accelerated science courses because of the opportunity to apply other scientific disciplines (physics, chemistry, biology) to understanding Earth processes and history. The push to move Earth sciences from non-college track to advanced placement has been around for almost a decade (Corbett 2000), yet

\footnotetext{
${ }^{7} \mathrm{http} / / /$ serc.carleton.edu/quantskills/activities/14009.html: "Teaching Quantitative Skills in the Geosciences: Environmental Footprint” by Christina Gallup (accessed 31 December 2008).

${ }^{8} \mathrm{http}: / /$ serc.carleton.edu/quantskills/activities/13812.html: "Teaching Quantitative Skills in the Geosciences: Floods over Time: Death and Destruction” by Anna Tary (accessed 31 December 2008).

${ }^{9} \mathrm{http} / / /$ serc.carleton.edu/quantskills/activities/13942.html: "Teaching Quantitative Skills in the Geosciences: Here We See It, But What's Beneath? Effective Geologic Cross-Section Problem Solving” by Rob Benson (accessed 31 December 2008).

${ }^{10} \mathrm{http}: / /$ serc.carleton.edu/quantskills/activities/13946.html: "Teaching Quantitative Skills in the Geosciences: Gulf anoxia course project" by Sadredin C. Moosavi and Anne Gerbensky(accessed 31 December 2008).

${ }^{11} \mathrm{http} / / / \mathrm{serc}$. carleton.edu/quantskills/workshop06/activities.html: "Activities submitted for the 2006 Infusing Quantitative Literacy into Introductory Geoscience Courses Workshop" (accessed 31 December 2008).

${ }^{12}$ http://serc.carleton.edu/quantskills/teaching resources/index.html: "Teaching Quantitative Skills in the Geosciences: Teaching quantitative skills in the geosciences: Activities for lab and class" (31 December 2008).
} 
many science curricula at the secondary level continue to offer Earth sciences as an alternative to more rigorous chemistry and physics classes. Geoscientists may need to work to change that perception by working with local high schools and school districts to demonstrate the intimate relationship of the geosciences with other science and mathematics disciplines. One of the high school teachers at the 2006 workshop worked with two university colleagues to develop a matrix of geologic content and the mathematical concepts involved. Together, they built a model syllabus for an Earth systems science course used at the advanced high school or introductory college level. ${ }^{13}$ Courses like these could serve to significantly change the perception of geosciences as well as the abilities of our incoming students.

A modified public attitude toward geosciences at the high school level may be the first step to altering college students' expectations of geosciences as the "easy out" for science requirements. But change is also needed in faculty and departments. Efforts at the College of William and Mary to integrate quantitative skills across the curriculum (Macdonald and Bailey 2000) and at the University of South Florida using spreadsheets in numerous geoscience courses ${ }^{14}$ have successfully changed student attitudes and expectations. Students now enter geosciences courses expecting to use mathematical skills to solve problems (McGee et al. 2007).

On a broader scale, faculty across disciplines can work together to carefully and creatively include quantitative skills within all introductory STEM courses so that students will expect the inclusion of QL. Both faculty and students may resist this effort initially; nonetheless, when faculty provide explicit expectations and support for QL, the culture of geoscience departments will begin to change, more realistically representing the quantitative nature of the science and promoting quantitative literacy in its students.

\section{Providing Support for Both Faculty and Students}

Participants at quantitative skills workshops emphasize that QL in the classroom needs an engaged and enthusiastic instructor, repetition (opportunities to build and grow mathematical ability) and an appropriate amount of support (e.g., scaffolding, repeated student success, heuristics, or hand-holding). One successful approach used at Highline Community College, is to provide support for entrylevel geoscience students through a shadow course called MathPatch (Baer et al.

\footnotetext{
${ }^{13} \mathrm{http}: / /$ serc.carleton.edu/quantskills/courses/14007.html: "Teaching Quantitative Skills in the Geosciences: Introduction to Earth System Science" by Aida Awad, Charles Dodd and Peter Selkin (accessed 31 December 2008).

${ }^{14} \mathrm{http}$ //serc.carleton.edu/quantskills/workshop06/vacherPPT.html: "Teaching Quantitative Skills in the Geosciences: Some Examples for Teaching Numeracy” by Len Vacher (accessed 31 December 2008).
} 
2005). Students who do not pass a pre-test are enrolled in this one-credit course that runs simultaneously with introductory geoscience. Students in the shadow course learn the math they need, just before they need it in the classroom. At Highline, student retention and success are positively correlated with enrollment in the MathPatch course (Baer et al. 2005). Recognizing the limitations that many geoscience departments have on time and course loads, we are developing a new Web resource that is designed to simulate a MathPatch-like course for students who would like to brush up on their quantitative skills (see Future Directions below).

\section{Resources for Teaching QL in the Geosciences}

If faculty are to take advantage of opportunities for QL development in the geosciences, they need quantitative resources that can be used in an introductory course. In the past decade, geoscience education literature has produced many good examples of activities and strategies for improving QL in entry-level courses (e.g., Bailey 2000b, b; Carlson 2000; DuPre and Evans 2000; Goforth and Dunbar 2000; Kenyon 2000; Nelson and Corbett 2000; Shosa et al. 2000; Stracher and Shea 2000; Wagner 2000). Increasing the use of mathematics in geoscience courses brings with it the need for new teaching methods ${ }^{15}$ and incorporation of new activities, problems, and projects. The faculty-constructed Teaching Quantitative Literacy Web resource provides ready-to-use activities, model syllabi and strategies for including quantitative content with the object of increasing the quantitative skills of introductory geoscience students. These Web resources build on the work of many who strive to increase quantitative thinking in the classroom and use strategies from both the geosciences and mathematics education communities.

\section{Tips and Techniques}

The Teaching Quantitative Literacy Web site recognizes that mathematics, the geosciences and other physical sciences are intimately intertwined and presents some ways that instructors can readily infuse quantitative concepts into any introductory geoscience course. Each individual page within the site contains tips and techniques for presenting quantitatively rich geologic content to students who may be unsure of their mathematical skills. The pages are interlinked to provide instructors with context and multiple opportunities to illustrate the mathematical concepts. Appropriate geoscience context is linked to mathematical under-

\footnotetext{
${ }^{15} \mathrm{http}: / /$ serc.carleton.edu/quantskills/methods/index.html: "Teaching Quantitative Skills in the Geosciences: Teaching Methods, Discussion Topics” (accessed 31 December 2008).
} 
pinnings, and instructors are given multiple examples of how to effectively convey both the geology and the math. For example, radioactive decay and deep time are intimately linked to big numbers and scientific notation and vice-versa. In all, there are six mathematical concepts tied to eight geologic contexts. Each of the pages has been blind peer reviewed.

Each of the mathematical concept pages uses the five pedagogical techniques discussed above to frame the topic. Instructors are given multiple ways to represent concepts, options for using technology, examples of working in groups, and the multiple geologic contexts in which a math concept can be used (thus, providing multiple opportunities to use a given mathematical concept). Because the math may be difficult to teach, we include activities for a variety of educational settings and tips for helping students to understand the math. References and resources are included so that instructors can learn more about a topic or explore other ways of teaching the same topic. The mathematical concepts included in the Teaching Quantitative Literacy site include:

- Big Numbers / Scientific Notation

- Exponential Decay

- Logarithms

- Probability
- Trigonometry and Angles

- Basic Graphing Skills

○ Understanding Trends

- Cumulative Percent Graphs

Linked to the concepts listed above are examples of geologic context for these quantitative skills. The geologic topics include:

- Radioactive Decay

- Deep Time

- Recurrence Interval

- Floods and Flooding
- Population Growth

- Stress and Strain

- Earthquake Magnitude

- Why Do Geologists Use Graphs?

Each of the geologic context pages includes "essential concepts" - the information that may represent sticking points for students but is critical when teaching a given topic quantitatively. Each geologic context page gives reasons and tips for teaching each concept quantitatively. At the bottom of each page, there are links to ready-made activities that can be downloaded and modified for use in class or lab. The array of topics that can be treated quantitatively and those that reiterate mathematical concepts multiple times in a course show the importance of geology as a tool to encourage QL in the general population. 


\section{Activities}

The Teaching Quantitative Skills in the Geosciences Web site has a growing set of community-built and tested activities for the classroom or laboratory. ${ }^{16}$ These resources cover all levels of the collegiate geoscience curriculum, from entrylevel to graduate. Many of the over 180 activities originated at workshops funded by NSF for the Digital Library of Earth System Education, whereas others were submitted directly by faculty who use these in their classrooms and lab, still others were built specifically for the Web site. Each of the activities is edited and approved by the editors of the site and many have been peer reviewed. The significant number of activities available on this site illustrates that geoscience can be an essential part of ensuring that students are able to deal with the quantitative world they live in, and provides the tools faculty need to adapt courses.

\section{Model Syllabi}

At a 2006 workshop, each faculty member or team of faculty members produced a model syllabus for quantitatively rich entry-level courses. These syllabi, which include a variety of courses from Natural Hazards to Environmental or Physical Geology, can be found at the workshop Web site. ${ }^{17}$ Each of these syllabi describes a course which promotes QL. Although some of these syllabi are "works in progress" and may not yet represent total infusion, each is based in best practices from the mathematics and geoscience education community and demonstrates the many ways that geosciences can serve to increase the QL of university and college students.

\section{Conclusions}

The geosciences provide ideal opportunities to increase the QL of a large portion of the college-educated populace. The "big-picture," visual, and observational aspects of geoscience make it an excellent model for using good pedagogical techniques from mathematics education such as the five "good ideas" detailed above. The quantitative nature of modern geosciences provides an exemplary discipline for contextual understanding of quantitative concepts with multiple representations. Students who experience the geosciences quantitatively will be

\footnotetext{
${ }^{16} \mathrm{http} / /$ serc.carleton.edu/quantskills/teaching_resources/index.html: "Teaching Quantitative Skills in the Geosciences: Activities for Lab and Class" (accessed 31 December 2008).

${ }^{17} \mathrm{http}$ ://serc.carleton.edu/quantskills/workshop06/browse courses.html: "Teaching Quantitative Skills in the Geosciences: Introductory Courses for Quantitative Literacy Workshop" (accessed 31 December 2008).
} 
better prepared to make informed decisions about environmental, public and political policies.

Many geoscientists are already successfully including QL in their entry-level courses. The Teaching Quantitative Literacy Web site, associated activities and syllabi provide faculty with tested and successful ways to further infuse their introductory classes with QL.

A concerted effort is needed to change public perception that the geosciences are descriptive and qualitative. Careful application of successful infusion of QL to the introductory geoscience courses realistically represents the current state of science and may have the effect of changing public perception of the geosciences as purely descriptive.

\section{Future Directions}

The Web site discussed here is designed to help instructors implement best practices in their classrooms. However, some of the onus for learning quantitative skills must also be put on the students. To this end, we have begun to work on a student resource that helps the student learn (or relearn) mathematical skills just before they need them in a geoscience course. These resources (The Math You Need, When You Need $\mathrm{It}^{\mathbf{1 8}}$ ) build on the Teaching Quantitative Literacy Web site and include lessons learned from classroom teaching, workshops, and research from the math and science education communities.

\section{Acknowledgments}

We thank workshop participants who have dealt with Quantitative Skills in the geosciences, especially those at the 2002 workshop who helped to enumerate the five good ideas and those at the 2006 workshop who thought so hard about the need for QL in introductory geoscience courses. We also thank Janet Anderson for so eloquently stating the good ideas; her untimely death in 2005 was a loss to all who are interested in QL. Reviews by Penelope J. Boston, Greg Herbert, Keith Sverdrup and three anonymous reviewers greatly improved this paper, and we are very thankful for their candid and helpful comments. This work is supported by grant number NSF-03-04762 from the Geoscience Directorate of the National Science Foundation (to CAM). Any opinions, findings, and conclusions or recommendations expressed in this manuscript are those of the authors and do not necessarily reflect views of the National Science Foundation.

\footnotetext{
${ }^{18}$ http://serc.carleton.edu/mathyouneed/index.html: "The Math You Need When You Need It: Math Tutorials for Students in Introductory Geosciences” by Jennifer M. Wenner and Eric M. Baer (accessed 31 December 2008).
} 


\section{References Cited $^{19}$}

Adams, Dennis M., and Mary E. Hamm. 1990. Cooperative Learning: Critical Thinking an Collaboration Across the Curriculum. Springfield, Illinois: Charles C. Thomas.

. 1998. Collaborative Inquiry in Science, Math, and Technology. Portsmouth, NH: Heinemann.

Alagic, Mara. 2003. Technology in the mathematics classroom: Conceptual orientation. Journal of Computers in Mathematics and Science Teaching 22 (4): 381-399.

AMATYC. 1995. Crossroads in Mathematics: Standards for Introductory College Mathematics before Calculus. Memphis, TN: American Mathematical Association of Two-Year Colleges.

Anderson, Janet, and Todd Swanson. 2004. Understanding our Quantitative World: Mathematical Association of America.

Baer, Eric M., Carla Whittington, Helen Burn, and Lisa Gilbert. 2005. MathPatch: A just-in-time approach to teaching quantitative skills and reducing attrition in an introductory geoscience course. Geological Society of America Abstracts with Programs 37 (7): 262.

Bailey, Christopher M. 2000a. A quantitative approach to introductory geology courses. Journal of Geoscience Education 48: 413-418. http://nagt.org/files/quantskills/jge-v48-p412-417.pdf

. 2000b. Rates of geologic processes: Problems for an introductory Geology Course. Mathematical Geology 32 (2): 151-158. http://dx.doi.org/10.1023/ A:1007571205384

Baker, Bernadette M., and Nancy L. Hagelgans. 2001. The CLUME Survey: Responses and summaries of comments. In Cooperative Learning in Undergraduate Mathematics: Issues that Matter and Strategies that Work, ed. E. C. Rogers, B. E. Reynolds, N. A. Davidson and A. D. Thomas. Washington, DC: The Mathematical Association of America.

Barrows, H. S., and R. N. Tamblyn. 1980. Problem Based learning: An approach to medical education. New York: Springer.

Boller, Bruce R., ed. 1999. Non-Traditional Teaching Styles in Physics, Issues of Education at Community Colleges: Essays by fellows in the Mid-Career Fellowship Program (1998-1999). Princeton, NJ: Princeton University.

Bykerk-Kauffmann, Ann. 1995. Using cooperative learning in college geology classes. Journal of Geological Education 43 (4): 309-316.

Carlson, Gaylen R. 2000. Density as an Integrating Topic to Promote Quantitative Reasoning in Non-Science Majors. Journal of Geoscience Education 48: 436-439. http://nagt.org/files/quantskills/Carlson-484436.pdf

Corbett, Robert G. 2000. Should we support establishment of Advanced Placement geology courses? The Professional Geologist 37 (11): 17.

Davidson, Neil A, ed. 1990. Cooperative Learning in Mathematics: A Handbook for Teachers. Menlo Park, CA: Addison-Wesley.

${ }^{19}$ All URLs were accessed 31 December 2008. 
Davidson, Neil A., Barbara E. Reynolds, and Elizabeth C. Rogers. 2001. Introduction to cooperative learning in undergraduate mathematics. In Cooperative Learning in Undergraduate Mathematics: Issues that Matter and Strategies that Work, ed. E. C. Rogers, B. E. Reynolds, N. A. Davidson and A. D. Thomas. Washington, DC: The Mathematical Association of America.

Dees, R. L. 1991. The role of cooperative learning in increasing problem-solving ability in a college remedial course. Journal for Research in Mathematics Education 22 (5): 409-421. http://dx.doi.org/10.2307/749188

Dufour-Janvier, B, N. Bednarz, and M. Belanger. 1987. Pedagogical considerations concerning the problem of representation. In Problems of Representation in the Teaching and Learning of Mathematics, ed. C. Janvier. Hillsdale, NJ: Lawrence Erlbaurm Associates.

Dupre, William R., and Ian Evans. 2000. Attempts at improving quantitative problemsolving skills in large lecture-format introductory geology classes. Journal of Geoscience Education 48: 431-435. http://nagt.org/files/quantskills/DupreEvans-v48n4p431.pdf

Fleming, Neil, and Colleen Mills. 1992. Not another inventory, rather a catalyst for reflection. To Improve the Academy 2: 137-149.

Fratesi, Sarah E., and H.L. Vacher. 2005. Using spreadsheets in geoscience education: Survey and annotated bibliography of articles in the Journal of Geoscience Education through 2003. Spreadsheets in Education 1 (3): 190-216: http://epublications.bond.edu.au/ejsie/vol1/iss 3/3.

- 2008. Scientific journals as fossil traces of sweeping change in the structure and practice of modern geology. Journal of Research Practice 4 (1): http://jrp.icaap.org/index.php/jrp/article/view/128/0.

Friedlander, Alex, and Michal Tabach. 2001. Promoting multiple representations in algebra. In The roles of representation in school mathematics ed. A. A. Cuoco. Reston, VA: National Council of Teachers of Mathematics.

Furman, Tanya, and Eileen Merritt. 2000. A data-intensive approach to studying climate and climate change in Africa. Journal of Geoscience Education 48 (4): 464-468. http://nagt.org/files/quantskills/jge-v48-p464-468.pdf

Gal, Iddo. 1997. Numeracy: Imperatives of a forgotten goal. In Why Numbers Count: Quantitative Literacy for Tomorrow's America, ed. L. A. Steen: College Board.

Gardner, Howard. 1983. Frames of Mind: The Theory of Multiple Intelligences. New York, NY: BasicBooks.

Goforth, Tom T., and John Dunbar, A. 2000. Student response to quantitative aspects of instruction in and introductory geology classroom. Mathematical Geology 32 (2): 187-202. http://dx.doi.org/10.1023/A:1007575306293

Greeno, James G., and Rogers P. Hall. 1997. Practicing representation: Learning with and about representations forms. Phi Delta Kappan 78: 361-367.

Guertin, Laura A. 2000. Using logic problems in introductory-level geoscience courses to develop critical reasoning and basic quantitative skills. Journal of Geoscience Education 48 (4): 423-427. http://nagt.org/files/quantskills/jge-v48-p423-427.pdf 
Hall-Wallace, Michelle K. 2000. Using linear regression to determine plate motions. Journal of Geoscience Education 42 (4): 455-458. http://nagt.org/files/quantskills/HallWallace-v48n4p455.pdf

Hancock, Gregory, and Cathy Manduca. 2005. Developing quantitative skills activities for geoscience students. EOS 86 (39): 355.

Heller, Patricia, and Kenneth Heller. 1999. Cooperative Group Problem Solving in Physics. Minneapolis, MN: University of Minnesota.

Jacobson, Michael, J., and Robert B. Kozma. 2000. Innovations in Science and Mathematics Education: Advanced Designs for Technologies of Learning. Mahwah, New Jersey: Lawrence Erlbaum Associates.

Jiang, Zhonghong, and Edwin McClintock. 2000. Multiple approaches to problem solving and the use of technology. Journal of Computers in Mathematics and Science Teaching 19 (1): 7-20.

Johnson, David W., and Roger T. Johnson. 1989. Cooperation and Competition: Theory and Research. Edina, MN: Interaction Book Company.

Johnson, David W., Roger T. Johnson, and Karl Smith. 1998. Cooperative learning returns to college: What evidence is there that it works? Change 20 (4): 26-35. http://dx.doi.org/10.1080/00091389809602629

Kaput, J. 1992. Technology and mathematics education. In Handbook of research on mathematics teaching and learning, ed. D. Grouws. New York: Macmillan.

Kenyon, Patricia M. 2000. Building quantitative skills in geoscience courses using homework assignments of increasing difficulty. Journal of Geoscience Education 48 (4): 418-422. http://nagt.org/files/quantskills/jge-v48-p418-422.pdf

Lutz, Timothy M., and LeeAnn Srogi. 2000. The role of a shadow course in improving the mathematics skills of geoscience majors. Journal of Geoscience Education 48 (4): 474-478. http://nagt.org/files/quantskills/LutzSrogi-v48n4p474.pdf

Macdonald, R. Heather, and Christopher McNeill Bailey. 2000. Integrating the teaching of quantitative skills across the geology curriculum in a department. Journal of Geoscience Education 48 (4): 482-486. http://www.nagt.org/files/quantskills/macdonald-v48n4p482.pdf

Macdonald, R. Heather, LeeAnn Srogi, and Glenn Stracher (eds.). 2000. Special Issue: Building the Quantitative Skills of Students in Geoscience Courses. Journal of Geoscience Education 48 (4). http://www.nagt.org/files/quantskills/macdonaldv48n4p409.pdf

Macdonald, R. Heather, Cathryn A. Manduca, David W. Mogk, and Barbara J. Tewksbury. 2004. Instructional Practices in introductory geoscience courses: Results of a national faculty survey. Eos, Transactions of the American Geophysical Union 85 (47): Abstract ED41A-0242.

Madison, Bernard L., and Lynn Arthur Steen, eds. 2004. Quantitative Literacy: Why Literacy Matters for Schools and Colleges. Princeton, NJ: National Council on Education and the Disciplines. http://www.maa.org/ql/qltoc.html

Manche, Emanuel P., and Stephen Lakatos. 1986. Obsidian hydration dating in the undergraduate curriculum. Journal of Geological Education 34 (1): 32-36.

Manduca, Cathryn A., R. Heather Macdonald, Mary E. Savina, Sam Patterson, M Mason, 
and Janet Anderson. 2001. Teaching quantitative skills in a geoscience context. EOS, Transactions of the American Geophysical Union 83 (47): 322.

Manduca, Cathryn A., Jennifer M. Wenner, Eric M. Baer, R. Heather Macdonald, Mary E. Savina, and Sam Patterson. 2005. Teaching quantitative skills in the geosciences. Geological Society of America Abstracts with Programs 37 (5): 10.

Manduca, Cathryn A., Eric M. Baer, Gregory Hancock, R. Heather Macdonald, Sam Patterson, Mary E. Savina, and Jennifer M. Wenner. 2008. Making undergraduate geoscience quantitative. $\operatorname{EOS} 89$ (16): 149-150. http://dx.doi.org/10.1029/2008 EO160001

Marshak, Stephen. 2007. Earth: Portrait of a Planet: W.W. Norton.

Martinez, Cindy, and Margaret A. Baker. 2006. Introductory geoscience enrollment in the United States, academic year 2004-2005. Ed. A. G. Institute, Geoscience Workforce Program. Washington, DC: American Geological Institute.

McGee, Dorien K., Christina E. Stringer, Ali Furmall, Judy Harden, Charles Connor, and H.L. Vacher. 2007. Contributions of spreadsheets across the curriculum modules to undergraduate geology courses at the University of South Florida: History and new directions. Geological Society of America Abstracts with Programs 39 (6): 559.

Millis, Barbara J., and Philip G. Cottell. 1998. Cooperative Learning for Higher Education Faculty. Phoenix, AZ: The Oryx Press.

National Council of Teachers of Mathematics (NCTM). 2000. Principles and Standards for School Mathematics. Reston, Va.: NCTM.

Nelson, Robert S., and Robert G. Corbett. 2000. Rock-density exercises for introductorylevel college courses. Journal of Geoscience Education 48 (4): 440-442. http://nagt.org/files/quantskills/NelsonCorbett-v48n4p440.pdf

Oberlander, Judith, and C. Talbert-Johnson. 2004. Using technology to support problembased learning. Action in Teacher Education 25 (4): 48-57.

Ousey, J. R., Jr. 1986. Modeling steady-state groundwater flow using micro-computer spreadsheets. Journal of Geoscience Education 34: 305-311.

Ozgun-Koca, S. Asli. 2001. The effects of multiple linked representations on student learning in mathematics. Proceedings of the Annual Meeting of the North American Chapter of the International Group for the Psychology of Mathematics Education 23: 997-1004.

Pape, Stephen J., and Mourat A. Tchoshanov. 2001. The role of representation(s) in developing mathematical understanding. Theory into Practice 40 (2): 118-127. http://dx.doi.org/10.1207/s15430421tip4002 6

Redish, Edward F., and Richard N. Steinberg. 1999. Teaching Physics: Figuring out what works. Physics Today 52: 24-30. http://dx.doi.org/10.1063/1.882568

Richardson, Randall M., and William G. McCallum. 2003. The third R in literacy. In Quantitative Literacy: Why Literacy Matters for Schools and Colleges, ed. B. L. Madison and L. A. Steen. Princeton, NJ: National Council on Education and the Disciplines. http://www.maa.org/q1/pgs99_106.pdf

Rogers, Elizabeth C., Barbara E. Reynolds, Neil A Davidson, and Anthony D. Thomas, eds. 2001. Cooperative Learning in Undergraduate Mathematics: Issues that Matter and Strategies that Work. Vol. 55, MAA Notes. Washington, DC: The Mathematical Association of America. 
Schoenfeld, Alan H. 1992. Learning to think mathematically: Problem solving, metacognition, and making sense in mathematics. . In Handbook of Research in Mathematics Teaching and Learning, ed. D. A. Grouws. New York, NY: Macmillan Publishing Co.

Schultz, James E., and Michael S. Waters. 2000. Why representations? Mathematics Teacher 93 (6): 448-453.

Shea, J. H. 1990. Mathematics in physical-geology textbooks. Journal of Geoscience Education 38:138-148.

- 1994. Mathematics (or the lack of it) in introductory-geology courses. Geological Society of America Abstracts with Programs 26 (4): 60.

Shosa, Jennifer D., Donald Woodrow, and Suzanne Orrell. 2000. Self-contained problem sets as a means of incorporating quantitative-skill development in existing introductory geoscience courses. Journal of Geoscience Education 48 (4): 427-430. http://nagt.org/files/quantskills/jge-v48-p427-430.pdf

Silver, Edward A., ed. 1985. Teaching and Learning Mathematical Problem Solving: Multiple Research Perspectives. Hilsdale, New Jersey: Lawrence Erlbaum Associates.

Smith, Aurora, and Gary Pun. 2005. How Does Earth Work? Physical Geology and the Process of Science: Prentice Hall.

Steen, Lynn Arthur, ed. 1988. Calculus for a New Century. Washington, DC: Mathematical Association of America.

— ed. 1997. Why Numbers Count: Quantitative Literacy for Tomorrow's America. New York, NY: The College Board.

— ed. 2001. Mathematics and Democracy: The case for Quantitative Literacy. Washington, DC: Woodrow Wilson National Fellowship Foundation. http://www.maa.org/ql/mathanddemocracy.html

- 2004. Achieving Quantitative Literacy: An Urgent Challenge for Higher Education: Mathematical Association of America.

Stevens, Reed. 2000. Who counts what as math? Emergent and assigned mathematics problems in a project-based classroom. In Multiple Perspectives on Mathematics Teaching and Learning, ed. J. Boaler. Westport, CT: Ablex.

Stracher, Glenn B., and James H. Shea. 2000. Enhancing quantitative skills of physicalgeology students with a geologic compass. Journal of Geoscience Education 48 (4): 447-449. http://nagt.org/files/quantskills/StracherShea-v48n4p447.pdf

Thompson, Patrick W. 1985. Experience, problem solving, and learning mathematics: Considerations in developing mathematics curricula. In Teaching and learning mathematical problem solving: Multiple research perspectives, ed. E. A. Silver. Hillsdale, NJ: Earlbaum.

Vacher, H. L. 2005. Computational geology 29-Quantitative literacy: Spread-sheets, range charts, and triangular diagrams. Journal of Geoscience Education 53 (3): 324-333. http://nagt.org/files/nagt/jge/columns/CG29-v53n3p324.pdf

Wagner, John R. 2000. Sneaking mathematical concepts through the back door of the introductory geology classroom. Mathematical Geology 32 (2): 217-229. http:// dx.doi.org/10.1023/A:1007579407201

Wenner, Jennifer M., Cathryn A. Manduca, R. Heather Macdonald, Sam Patterson, and 
John McDaris. 2004. Teaching quantitative skills in the geosciences: Resources for faculty. Eos, Transactions of the American Geophysical Union 84 (47): Abstract ED41A-2445.

Wenner, Jennifer M., Eric M. Baer, and Cathryn A. Manduca. 2005. Teaching Quantitative Literacy: A Web site to help instructors make introductory geoscience courses more quantitative. Geological Society of America Abstracts with Programs 37 (7): 157.

Wenner, Jennifer M., Cathryn A. Manduca, and Eric M. Baer, 2006a. The role of introductory geosciences in quantitative literacy. Eos, Transactions of the American Geophysical Union 87 (52): Abstract ED11B-1198.

Wenner, Jennifer M., Eric M. Baer, and Cathryn A. Manduca. 2006b. Infusing quantitative literacy into introductory courses: Best practices, courses and activities. Geological Society of America Abstracts with Programs 38 (7): 496. 